Response, part of a Special Feature on Law and Social-Ecological Resilience

\title{
Scale mismatches and reflexive law
}

\author{
Graeme S. Cumming ${ }^{1}$
}

Key Words: democracy; institution; law; reflexivity; scale

Garmestani and Benson (2013) deal with a problem that is receiving increasing attention in the study of social-ecological systems: that of scale mismatches and ways of resolving them. Scale mismatches have been defined as occurring when the scale of environmental variation and the scale of social organization in which the responsibility for management resides are aligned in such a way that one or more functions of the social-ecological system are disrupted, inefficiencies occur, and/or important components of the system are lost (Cumming et al. 2006). Mismatches between the scales of ecological processes and the institutions that are responsible for managing them are thought to lead to a decrease in socialecological resilience, including an increased likelihood of mismanagement of natural resources and an attendant decrease in human well-being.

Cumming et al. (2006) considered that solutions to scale mismatches usually require institutional changes at more than one hierarchical level. Further, since institutions are usually developed with explicit functions (goals) in mind, resolving scale mismatches also demands exchanges between actors and institutions at different hierarchical levels to determine what the functions of each should be.

Garmestani and Benson (2013) propose that a legal system that exhibits the property of reflexivity - in the sense that the creation of rules (laws) incorporates not only a top-down imposition of rules by the sovereign but also a formalized feedback from the people to the sovereign (Dorf 2003) - will contribute to the resolution of scale mismatches. According to the authors, reflexive law is expected to establish procedural and organizational norms but not to determine the final outcome. In other words, reflexive law is intended to provide the means to allow the people to be heard in the process of law creation, and to find locally appropriate solutions, within the confines and restraints of a more traditional and top-down legal system.

While this idea may appear superficially to be a simple appeal for a more democratic and inclusive rule-creation process, I find it, on deeper reflection, to be quietly revolutionary. Scale in the social sciences includes dimensions of power, not just the elements of space and time that biophysical scientists most commonly focus on. To draw an ecological parallel, the proposal for reflexive law-making is not a simple "A influences B influences A" feedback of the kind by which lions
("A") eat antelope ("B"), and the numbers of antelope in turn regulate the lion population. Nor is it a typical bottom-up feedback of the kind by which grass availability regulates antelope numbers and in so doing, regulates the lion population. It is more akin to the antelope getting together and demanding that the lion should not eat them. Another alternative must be found that also takes into account the needs of the lions and of the grass. But the catch here, and the part that worries me about pushing for bottom-up law construction by people, is that the lions must do what lions have evolved to do - eat antelope - if the lions themselves are to survive and if system function in its current form is to be maintained. While the antelope might not like the regulatory functions that are performed by the lion (despite the visible evidence of their success in the form of plenty of grass), there is no obvious alternative.

In the real world, as discussed by the authors, reflexive lawmaking would clearly have to be implemented in tandem with more traditional legislation and in a very controlled manner. Good governance lies at the heart of successful solutions. Without the right kind and number of checks and balances, reflexive rule creation might easily lay a foundation for extremism, for inaction and system paralysis, or for other kinds of resilient and highly problematic system configurations. Indeed, speaking as someone who grew up in Zimbabwe, the potential for corrupt governments and individuals to use the legal system to achieve their own political and economic objectives is a continual concern. Complex systems are often unpredictable, and the creation of new feedbacks might produce both benefits and costs in unpredictable ways.

The potential for abuse of a reflexive law system - whether through unreasonable or inappropriate demands, or capture of the system by one or more groups, or the potential implications for innovative managers of the threat of legal action - is not the only potential pitfall in the proposed approach. The question of time is another problem for the implementation of a reflexive legal framework for environmental management. Scale mismatches can be spatial, temporal, or functional (Cumming et al. 2006). The completion of democratic processes takes time, and the legal framework changes slowly. Can legal institutions ever respond fast enough to ongoing system change to make a difference? I suspect that the authors would argue that a reflexive law framework could be designed in such a way as to facilitate more rapid problem-solving and 
greater regulatory flexibility at local levels, in which case their approach might offer a key step forward in the solution of scale mismatches.

Most of these questions are difficult to answer in the absence of further evidence. The only solution here appears to be to proceed slowly and cautiously, with institutional creation and management going hand in hand with small incremental experiments. As we experiment with different ways of developing and implementing laws, the resulting learning can be used to improve subsequent efforts. In this sense, the authors are fully justified in using adaptive management to inform their approach to the legal framework that is outlined in their paper.

Regardless of whether or not reflexive law provides the ultimate solution, alterations to the legal and regulatory system to better deal with scale mismatches are likely to be an important part of enhancing and developing long-term resilience in social-ecological systems. I applaud the authors for taking on this difficult topic and for having the courage to propose a first outline from which to begin the debate.

Responses to this article can be read online at:

http://www.ecologyandsociety.org/issues/responses.

php/5407

\section{Acknowledgments:}

I am grateful to the editors of the special feature for inviting this response. My research programme is supported by the National Research Foundation of South Africa, the James $S$. MacDonnell Foundation, and the University of Cape Town.

\section{LITERATURE CITED}

Cumming, G. S., D. H. M. Cumming, and C. L. Redman. 2006. Scale mismatches in social-ecological systems: causes, consequences, and solutions. Ecology and Society 11(1): 14. [online] URL: http://www.ecologyandsociety.org/vol11/iss1/ art14/.

Dorf, M. C. 2003. The Domain of Reflexive Law. Cornell Law Faculty Publications. Paper 86. [online] URL: http:// scholarship.law.cornell.edu/facpub/86.

Garmestani, A. S., and M. H. Benson. 2013. A framework for resilience-based governance of social-ecological systems. Ecology and Society 18(1): 9. http://dx.doi.org/10.5751/ ES-05180-180109 